\title{
ANALISA JENIS LIMBAH KAYU DI JEPARA
}

\author{
Gun Sudiryanto, Suharto \\ Fakultas Sains dan Teknologi, UNISNU Jepara \\ gun@unisnu.ac.id
}

\begin{abstract}
Wood processing for industry in Jepara also produces a lot of waste. The types of waste vary greatly, from logging, when logs enter the sawing, processing to final sanding before finishing. The number of types of waste needs to be assessed in terms of quantities and types so that in the future after identification of the type and amount. To record and analyze the types of wood waste used in the furniture industry in Jepara. In addition to getting data on the types of wood waste, this study also examined the estimated amount of wood waste in Jepara. So to analyze the type and amount of wood waste in Jepara the writer uses descriptive analysis method because it is suitable to find out the phenomenon that is currently ongoing. The furniture industry in Jepara turned out to produce a lot of waste. From the researchers' calculations, the amount of wood used in Jepara can reach $58.85 \%$. This is when assessed from living trees which are then cut down, resulting in half reaching more waste. If the calculation starts from the sawing of division until the final process, the researchers calculated that the waste reaches $37.08 \%$. So the material that can be used from Perhutani wood reaches $62.92 \%$. Meanwhile, if the product is without carving, the resulting waste is $34.21 \%$ and the wood used to make furniture reaches $65.79 \%$.
\end{abstract}

Keywords: amount, type, waste, furniture

\begin{abstract}
Abstrak
Pengolahan kayu untuk industry di Jepara juga menghasilkan banyak limbah. Jenis limbah sangat bermacam, dari mulai penebangan, saat kayu log masuk penggergajian, pengolahan hingga pengamplasan akhir sebelum dilakukan finishing. Banyaknya jenis limbah tersebut perlu dikaji jumlah dan jenisnya sehingga dimasa yang akan datang setelah ada identifikasi jenis dan jumlahknya. Untuk mendata dan menganalisa jenis limbah kayu yang digunakan dalam industry mebel di Jepara. Selain mendapatkan data jenis limbah kayu, penelitian ini juga mengkaji jumlah perkiraan limbah kayu yang ada di Jepara. Maka untuk menganalisa jenis dan jumlah limbah kayu di Jepara penulis menggunakan metode deskriptif analisis karena dirasa cocok untuk mengetahui fenomena yang saat ini sedang berlangsung. Industri furnitur di Jepara ternyata menghasilkan limbah yang tidak sedikit. Dari perhitungan peneliti ternyatalimbah kayu yang digunakan di Jepara dapat mencapai $58,85 \%$. Hal ini bila dinilai dari pohon hidup yang kemudian ditebang, sehingga menghasilkan limbah mencapai separuh lebih. Apabila perhitungannya mulai saat penggergajian pembelahan hingga proses akhir yang dalam perhitungan peneliti limbahnya mencapai $37,08 \%$. Jadi bahan yang dapat digunakan dari kayu Perhutani mencapai $62,92 \%$. Sementara bila produk tersebut tanpa ukiran maka limbah yang dihasilkan adalah $34,21 \%$ dan kayu yang digunakan untuk pembuatan mebel mencapai $65,79 \%$.
\end{abstract}

Kata kunci: jumlah, jenis, limbah, furniture

\section{PENDAHULUAN}

Industri furnitur merupakan industri yang mencakup pengolahan bahan baku berupa kayu, rotan, atau bahan baku lainnya yang diproses untuk meningkatkan nilai tambah dan manfaat yang lebih tinggi menjadi produk barang jadi furnitur. Indonesia merupakan salah satu produsen utama furnitur dunia yang memiliki potensi bahan baku yang besar dan bervariasi Produk furnitur Indonesia dikenal memiliki daya saing yang cukup tinggi di pasar internasional. Daya saing tersebut berupa desain yang unik dan produk furnitur dengan bahan baku yang khas seperti rotan, bambu, dan kayu jati dibandingkan furnitur yang diproduksi oleh negara lain. Daerah produksi furnitur terdapat hampir di seluruh propinsi, dengan konsentrasi produsen yang 
cukup tinggi terletak di daerah Jepara, Klaten, Pasuruan, Sidoarjo, Gresik, Cirebon, Sukoharjo, Surakarta, dan Jabodetabek (AMKRI, 2015).

Ekspor olahan kayu dari Jepara meningkat dari 110 juta dollar AS pada tahun 2014 menjadi 150 juta dollar AS pada tahun 2015. Jumlah ekspor dari Jepara merupakan 10 persen dari total ekspor nasional sebesar 1,5 miliar dollar AS. Menurut Herry Purnomo, leader di Center for International Foresty Reseach (CIFOR), lembaga bergerak di bidang riset kehutanan global mengatakan, meski dunia mebel mulai kesulitan pekerja, namun nilai ekspor dari Jepara tetap tinggi. Ekspor dari para pengusaha pun beragam mulai dari Uni Eropa, Amerika, Timur Tengah, Australia hingga negara tetangga seperti Malaysia, Singapura hingga India. Pada 2007, perajin ukir dari Jepara ada 7 kategori dengan jumlah total 15.000 perajin. Namun pada 2010, jumlah mereka menurun hingga 11.481 perajin. Menurunnya jumlah perajin tidak lepas dari seleksi alam, serta banyaknya spekulan di industri tersebut. Sebelumnya neraca perdagangan Provinsi Jawa Tengah (Jateng) ke Uni Eropa, terutama ke Denmark mengalami peningkatan cukup signifikan sepanjang 2015. Ekspor sejumlah produk terutama furniture, diterima dengan baik di negeri tersebut. Total ekspor ke Denmark sepanjang 2015 lalu mencapai 7,1 juta dollar AS. Jumlah tersebut disumbang dari kategori furniture, kayu olahan dan filamen buatan. Nilai tersebut diyakini akan bertambah seiring produk kayu Indonesia bisa masuk ke Eropa tanpa melalui proses pemeriksaan uji tuntas. (https://ekonomi.kompas.com/read/2017/10/04 /220000226).

Dari nilai ekspor yang ada pemanfaatan kayu di Jepara kurang lebih ada 2.500 kubik per bulan. Walaupun menurut Bapak Andi selaku PLT Bupati yang meyakini secara kasat mata terkait perkayuan kebutuhan di Jepara tidak hanya di angka itu.Angka tersebut hanya berdasarkan pada perhitungan suplai kebutuhan ekspor. Masih banyak angka jumlah kebutuhan kayu yang diluar itu. beliau mencontohkan, banyak dari industri olahan kayu di Jepara yang mensuplai untuk kebutuhan pasar regional dan nasional. Untuk bisa mendata secara riil, maka Dinas
Perindustrian dan Perdagangan (Disperindag) diharapkan dapat memulai data dari kebutuhan kayu.Setelah didapatkan jumlah riil kebutuhan kayu di Jepara. Maka tahap selanjutnya akan dilakukan satu kajian dan perumusan untuk mencari satu solusi untuk kembali menggeliatkan perekonomian permebelan Jepara untuk bangkit (https://jepara.go.id/2018/09/04/pemkab-

jepara-akan-data-distribusi-kayu)

Dari banyaknya penggunaan kayu tersebut, ternyata pengolahan kayu untuk industry di Jepara juga menghasilkan banyak limbah. Jenis limbah sangat bermacam, dari mulai penebangan, saat kayu log masuk penggergajian, pengolahan hingga pengamplasan akhir sebelum dilakukan finishing. Banyaknya jenis limbah tersebut perlu dikaji jumlah dan jenisnya sehingga dimasa yang akan datang setelah ada identifikasi jenis dan jumlahknya, akan dapat dimanfaatkan menjadi bahan untuk industry lainnya yang lebih bermanfaat. Seperti penelitian yang dilakukan Adam dkk (2019) dimana limbah kayu dapat dimanfaatkan sebagai bahan baku untuk komposit polimer kayu dalam mencetak 3D Printer.

Penelitian Djoko (2009) menyebutkan bahwa industri penggergajian kayu menghasilkan limbah sebesar 40,48 \% volume, terdiriatas sebetan (22,32 \%), potongan kayu $(9,39 \%)$ dan serbuk gergaji $(8,77 \%)$. Sedangkanlimbah industri kayu lapis sebesar $54,81 \%$ volume dengan rincian potongan dolok (3,69\%), sisa kupasan dolok $(18,25 \%)$, venir basah $(8,50 \%)$, penyusutan $(3,69 \%)$, venirkering $(9,60 \%)$, pengurangan tebal (venir kering) $(1,90 \%)$, potongan tepi kayu lapis $(3,90 \%)$, serbuk gergaji $(2,2 \%)$ dan debu kayu lapis (3,07\%). Pemanfaatan pada kedua jenislimbah tersebut antara lain sebagai bahan bakar, inti papan blok, papan blok, papanpartikel, dan sambungan venir inti, atau venir belakang kayu lapis.

Penelitian Adam dkk (2019) menyatakan industri mebel Michigan menghasilkan lebih dari 150 ton / hari limbah berbasis kayu, yang dapat didaur ulang menjadi komposit polimer kayu (WPC). Studi ini menyelidiki kelayakan menggunakan limbah furnitur sebagai bahan baku untuk filamen printer 3-D untuk menghasilkan 
komponen furnitur. Prosesnya meliputi: potongan papan penggilingan / penggilingan yang terbuat dari LDF / MDF / LDF dan melamin / papan partikel / kertas yang diresapi dengan resin fenolik; pra-pencampuran bubuk berbasis kayu dengan biopolymer poly lactic acid (PLA), diekstraksi dua kali melalui recyclebots open-source untuk membuat filamen WPC cetak 3-D yang homogen, dan mencetak dengan printer 3-D berbasis-FFF open source. Hasilnya menunjukkan ada peluang signifikan bagi WPC komposit berbasis limbah untuk digunakan sebagai filamen pencetakan 3-D.

Tujuan penelitian ini adalah untuk mendata dan menganalisa jenis limbah kayu yang digunakan dalam industry mebel di Jepara. Selain mendapatkan data jenis limbah kayu, penelitian ini juga mengkaji jumlah perkiraan limbah kayu yang ada di Jepara.

\section{METODE PELAKSANAAN}

Penelitian ini menggunakan metode deskriptif untuk menggambarkan keadaan secara riil di lapangan. Metode deskriptif berfungsi untuk menggambarkan atau memberi gambaran terhadap objek yang diteliti melalui data atau sampel yang telah terkumpul sebagaimana adanya tanpa melakukan analisis dan membuat kesimpulan yang berlaku untuk umum(Sugiono, 2014). Dengan kata lain penelitian deskriptif analitis mengambil masalah atau memusatkan perhatian kepada masalah-masalah sebagaimana adanya saat penelitian dilaksanakan, hasil penelitian yang kemudian diolah dan dianalisis untuk diambil kesimpulannya. Maka untuk menganalisa jenis dan jumlah limbah kayu di Jepara penulis menggunakan metode deskriptif analisis karena dirasa cocok untuk mengetahui fenomena yang saat ini sedang berlangsung.

Untuk mendapatkan data dilapangan maka dilakukan dengan cara observasi dan wawancara. Observasi adalah pengamatan meliputi kegiatan pemusatan perhatian terhadap suatu objek dengan menggunakan seluruh indera(Arikunto, 2013). Dalam penelitian ini, peneliti menggunakan observasi terstruktur dan nonpartisipan. Observasi terstruktur adalah observasi yang dipersiapkan tentang apa yang akan diobservasi berupa rambu-rambu pengamatan meskipun sederhana dan berkembang di lapangan. Sedangkan observasi nonpartisipan yaitu peneliti tidak ikut terlibat dalam kegiatan, tetapi hanya sebagai pengamat. Peneliti melakukan observasi terhadap proses pembuatan furniture di Jepara dengan melihat langsung mulai proses penebangan kayu, penggergajian, pengolahan atau perakitan, pengukiran sebagai bagian khas furniture Jepara hingga pengamplanan pra finishing, yang akhirnya akan memberikan dampak limbah kayu yang dihunakan.

Selain menggunakan metode observasi, peneliti juga melakukan metode wawancara untuk mendapatkan data dari pengrajin. Wawancara adalah pertemuan dua orang untuk bertukar informasi dan ide melalui tanya jawab, sehingga dapat dikonstruksikan makna dalam suatu topik tertentu (Sugiyono, 2014). Beberapa macam wawancara, yaitu wawancara terstruktur, semiterstruktur, dan tidak terstruktur.Peneliti menggunakan teknik wawancara yang semiterstruktur, wawancara ini menggunakan pedoman wawancara yang telah tersusun secara sistematis. Wawancara ini masuk dalam kategori in-dept interview (wawancara mendalam) yang pelaksanaannya lebih bebas serta terbuka dengan meminta pendapat dan ide-ide dari informan. Serta dilakukannya wawancara ini agar penulis mendapat data yang valid dan dapat dipertanggung jawabkan mengenai jenis dan jumlah limbah kayu yang ada di Jepara.

\section{HASIL DAN PEMBAHASAN}

Pada pembahasan penelitian ini dilakukan dengan menganalisa proses pembuatan furniture dan dari proses tersebut, maka akan diketahui rendemen atau limbah dari proses pembuatan furniture di Jepara. Dalam proses pengerjaanfurniture dan olahan kayu di Jepara biasanyaterlebih dulu pengamatan pada gambar yang akan dibuat, setelah gambar dimengerti dan dipahami betul-betul, barulah penghitungan bahan yang akan dirajut sekaligus mengontrol kualitas bahan danuntuk mendapat hasil yang memuaskan dilakukan proses-proses pengerjaan sebagai berikut:

1. Penebangan kayu. Dalam proses pembuatan mebel, langkah pertama 
adalah penebangan kayu. Untuk kayu perhutani, biasanya akan dilakukan penderesan terlebih dahulu terutama untuk kayu Jati. Pendesersan dilakukan untuk mematikan kayu dengan menghilangkan kulit kayu secara melingkar pada pangkal pohon. Proses ini juga untuk mengeringkan kayu secara alami sebelum kayu ditebang. Proses penebangan kayu menghasilkan limbah $7,67 \%$ berupa ranting dan dahan kecil pada pohon, $8,23 \%$ akar pohon dan $0,98 \%$ serbuk kayu gergajian saat penebangan dan pemotongan.

2. Pembelahan Kayu, proses pembelahan dilakukan di tempat penggergajian. Di Jepara umum ditemukan penggergajian Lori dengan system rel dan juga system pondong. Sementara gergaji system horizontal belum ditemukan di Jepara. System penggergajian menggunakan lori dan pondong akan membuat serbuk kayu lebih banyak, karena gergaji ini umumnya memiliki ketebalan $3 \mathrm{~mm}$. sehingga kayu akan menghasilkan limbah serbuik gergaji dalam jumlah yang lebih banyak. Untuk pembelahan kayu akan menghasilkan limbah gergajian sebanyak $0,89 \%$ dan sebetan berupa kayu pinggiran sebanyak $15,58 \%$ dan kulit kayu terutama untuk kayu dari hutan rakyat sebanyak $4,87 \%$.

3. Pembahanan. Setelah kayu dibelah menjadi papan, maka pengrajin akan memulai pembuatan furniture melalui pengamatan pada gambar, langkah ini dilakukan setelah pemilihan bahan baku. Pemilihan papan disesuaikan dengan mal auatu komponen yang diperlukan nantinya. Bila komponen lebar seperti daun meja maka dapat diambilkan dari papan dari tengah kayu sehingga warnanya bagus dan akan menggunakan sedikit sambungan. Namun bila untuk sunduk maka akan digunakan kayu yang lebih pinggir akan menghemat kayu, juga menggunakan kayu yang tidak terlalu lebar. Untuk proses pemotongan ini yang lurus menggunakan gergaji piring atau bandshaw, dan untuk komponen lengkung menggunakan gergaji pita atau gergaji bengkok. Sementara untuk bagian ukiran menggunakan jigsaw, atau biasa disebut gergaji bobok oleh masyarakat Jepara. Pada tahap pemotongan ini menghasilkan limbah potongan sebanyak $11,67 \%$ dan serbuk gergaji sebanyak $0,89 \%$.

4. Penghalusan Komponen, Setelah dilakukan pemotongan sesuai dengan komponen yang dibutuhkan kayu tersebut lalu dihaluskan dengan mesin planer, pada tahap ini menghasilkan limbah $1,56 \%$ limbah serbuk planer yang agak kasar. Dahulu proses ini dilakukan secara manual dengan menggunakan alat sederhana berupa unduk kodok dan unduk panjang. Pada proses penghalusan menggunakan unduk dahulu, akan menghasilkan limbah berupa pasahan yang memanjang.

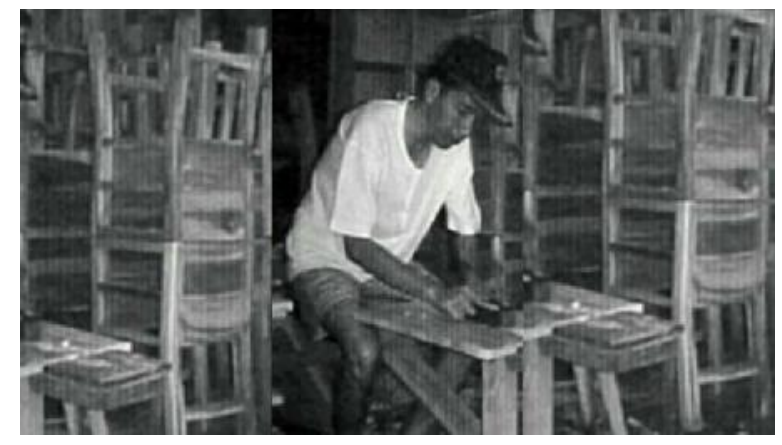

Gambar 1. Alat yang digunakan Bapak Jokowi adalah Unduk Kodok untuk meraut dan menghaluskan kayu

5. Pengukiran, pada tahap ini pengrajin melakukan pengukiran dengan beberapa macam teknik. Ada yang menggunakan teknik manual dengan cara diukir menggunakan tangan, ada juga yang menggunakan bantuan mesin profil untuk membuat motif minimalis, beripa cekungan atau cembungan bulat pada bidang. Dan teknik terbaru adalah menggunakan mesin CNC. Pengukiran menggukanan mesin CNC banyak digunakan warga Jepara untuk membuat logo, kaligrafi dan ukiran untuk bidang rata yang banyak. Untuk pengukiran ratarata di Jepara menghasilkan limbah yang sedikit yakni hanya $2,87 \%$. Untuk jenis furniture dengan desain hewan atau patung seperti halnya kursi kepiting, kursi kerang dimana proses pengukiran juga 
dibantu menggunakan chainsaw, memang menghasilkan limbah yang banyak yakni hingga $38,56 \%$. Akan tetapi ukiran seperti ini tidak banyak dibuat di Jepara dan hanya ada di desa Mulyoharjo dan desa Sukosono dengan menggunakan kayu trembesi. Pada pembuatan furniture patung juga tanpa melalui proses pembelahan dan juga pembahanan seperti halnya pembuatan furniture lainnya. Pembuatan patung biasanya dari kayu bulat utuh yang langsung dipotong dan dibentuk menggunakan chainsaw dan langsung diukir, sehingga limbahnya banyak.

6. Perakitan Komponen, Perakitan ini dikerjakan dengan ketepatan ukuran agar tidak miring dan goyang dan jadi sesuai bentuk yang diinginkan.karenatiap furniture membutuhkan teknik dan pengerjaan yang berbeda maka proses ini pun akan menghasilkan limbah. Pada tahap ini pengrajin akan membuat sunduk, purus dan sambungan pada papan. Selain itu dilakukan pengeboran untuk mengaitkan komponen yang satu dengan lainnya. Pada tahap ini akan menghasilkan limbah sebanyak $1,12 \%$.

7. Finishing, tahap akhir dalam pembuatan produk furniture Jepara ini sangat menentukan produk dalam segi kualitas dan estetikanya. Dalam kegiatan ini dilakukan proses pengamplasan kasar dan amplas halus untuk selanjutnya dilakukan finishing spray atau kuas. Pada tahap pengamplasan menghasilkan limbah serbuk amplasan yang halus dalam skala sangat kecil yakni hanya $0,09 \%$. Kebanyakan di Jepara saat ini menggunakan jenis finishing melamine warna natural. Di gunakannya jenis finishing melamine karena mempunyai keunggulan sebagai berikut: cepat kering, daya tutup pori-pori lebih baik dari jenis finishing N/C system, sangat gloss, daya tahan terhadap air dan alcohol sangat baik dan lapisan yang terbentuk, tidak larut oleh thinner. Selain menggunakan bahan dasar thinner, saat ini banyak juga pengusaha yang telah beralih menggunakan finishing berbahan dasar air yang lebih ramah lingkungan, walaupun bahan ini lebih mahal disbanding bahan menggunakan thinner.

Pelaksanaan usaha furniture Jepara ternyata menghasilkan limbah yang cukup banyak. Untuk itu perlu ada pemahaman bagi para pengusaha meubel di Jepara agar dapat melakukan evaluasi, efisiensi atau juga pemanfaatan limbah agar dapat menjadi produk yang bernilai jual. Berikut adalah perhitungan peneliti berdasarkan observasi dan wawancara dengan beberapa pengusaha di Kabupaten Jepara.

Tabel 1. Perkiraan Rata-rata Limbah Meubel di Jepara

\begin{tabular}{|c|c|c|c|}
\hline No & Proses & Jenis Limbah & Jumlah \\
\hline \multirow[b]{3}{*}{1} & \multirow{3}{*}{ Penebangan } & Ranting & 7.67 \\
\hline & & Akar & 8.23 \\
\hline & & $\begin{array}{l}\text { Serbuk } \\
\text { Gergaji }\end{array}$ & 0.98 \\
\hline \multirow{3}{*}{2} & \multirow{3}{*}{ Pembelahan } & $\begin{array}{l}\text { Sebetan } \\
\text { Pinggir }\end{array}$ & 15.58 \\
\hline & & Kulit & 4.87 \\
\hline & & $\begin{array}{l}\text { Serbuk } \\
\text { Gergaji }\end{array}$ & 2.32 \\
\hline \multirow[b]{2}{*}{3} & \multirow[b]{2}{*}{ Pembahanan } & $\begin{array}{l}\text { Potongan } \\
\text { kayu }\end{array}$ & 11.67 \\
\hline & & $\begin{array}{l}\text { Serbuk } \\
\text { Gergaji }\end{array}$ & 0.89 \\
\hline 4 & $\begin{array}{l}\text { Penghalusan } \\
\text { Komponen }\end{array}$ & Limbah Serut & 1.56 \\
\hline 5 & Ukiran & Tatal Ukiran & 2.87 \\
\hline 6 & Perakitan & $\begin{array}{l}\text { Potong dan } \\
\text { serbuk }\end{array}$ & 1.12 \\
\hline 7 & Finishing & $\begin{array}{l}\text { Serbuk } \\
\text { Amplas }\end{array}$ & 0.09 \\
\hline \multicolumn{3}{|c|}{ Jumlah Total } & 58.85 \\
\hline
\end{tabular}

Dari tabel di atas, dapat dilihat bahwa ternyata limbah kayu yang digunakan di Jepara dapat mencapai $58,85 \%$. Hal ini bila dinilai dari pohon hidup yang kemudian ditebang, sehingga menghasilkan limbah mencapai separuh lebih. Akan tetapi total limbah tersebut tentunya berbeda dari tiap produk yang dihasilkan dan berbeda dari sisi desain mebel yang diproduksi. Apabila penggunaan kayu dari muali pembelian di Perhutani dan tentusaja hal tersebut tanpa ranting atau dahan kecil, akar dan kulit, maka 
limbah yang dihasilkan lebih sedikit yakni hanya $37,08 \%$.

Perhitungan ini juga menjadi perhatian dalam pelaksanaan perhitungan limbah kayu dalam SVLK yakni dari pembelian kayu Log dan perhitungannya mulai saat penggergajian pembelahan hingga proses akhir yang dalam perhitungan peneliti limbahnya mencapai $37,08 \%$. Jadi bahan yang dapat digunakan dari kayu Perhutani mencapai 62,92\%. Sementara bila produk tersebut tanpa ukiran maka limbah yang dihasilkan adalah 34,21\% dan kayu yang digunakan untuk pembuatan mebel mencapai $65,79 \%$. Pembuatan produk Garden misalnya tidak banyak menghasilkan limbah karena prosesnya setelah kayu terbelah langsung di mal sesuai gambar, dipotong, dihaluskan dan dirakit serta diamplas, dan kayu yang digunakan menurut peneliti setelah observasi dan melakukan wawancara dapat mencapai $65,79 \%$.

Dari apa yang disampaikan bapak PLT Bupati Jepara bahwa penggunaan kayu di Jepara mencapai $2500 \mathrm{M}^{3}$ tiap bulan dan bila dikalikan 12 atau dalam satu tahun menggunakan kayu mencapai $30,000 \mathrm{M}^{3}$. Sehingga tiap tahunnya Jepara menghasilkan limbah mencapai $17,355 \mathrm{M}^{3}$. Itu apabila dihitung dari saat pohon berdiri, dan bila dari log kayu maka limbah yang dihasilkan Jepara tiap tahunna mencapai $11,240 \mathrm{M}^{3}$.

Hasil ini juga dapat menjadi acuan bagi pengusaha dalam pembuatan mebel terutama dalam pembuatan harga pokok produksi. Selain itu bagi para pembeli juga dapat menawar dengan wajar, karena bila dihitung, kayu yang digunakan pengrajin hanya mencapai $65,79 \%$. Jadi apabila harga satu meter kubik kayu jati ukuran midline $30 \mathrm{an}$ dengan harga Rp. 10,000,000 maka kayu yang digunakan hanya bernilai Rp.6,579,000 sementara yang mencapai limbah mencapai Rp. 3,421,000. Jadi wajar bila dari perhitungan kayu saja, para pengrajin menaikkan harga $35 \%$ dari harga kayu normal. Malah tidak wajar bila harga barang meubel bila dengan kualitas bagus dan bahannya kayu jati ynag bagus ternyata harga jualnya lebih rendah dari perkiraan harga kayu tersebut. Perhatian tersebut untuk memberikan kepada masyarakat luas akan banyaknya ppenjual online, yang menjual barang yang kadangkala dibawah harga kayu mentahnya, sehingga dapat dipastikan bahwa penjual semacam itu pastilah penipuan.

Untuk itu perlu pemahaman bersama bahwa kayu yang digunakan selain akan menghasilkan limbah, nantinya juga membutuhkan proses pengerjaan yang rumit sehingga jurnal ini dapat dijadikan rujukan tidak hanya dari sisi ilmiah, tapi juga secara umum bagi pengrajin agar dapat melakukan perhitungan harga pokok produksi secara benar berdasarkan penggunaan kayu dan juga bagi konsumen agar memahami kayu yang digunakan.

\section{SIMPULAN}

Industri furnitur di Jepara ternyata menghasilkan limbah yang tidak sedikit. Dari perhitungan peneliti ternyatalimbah kayu yang digunakan di Jepara dapat mencapai 58,85\%. Hal ini bila dinilai dari pohon hidup yang kemudian ditebang, sehingga menghasilkan limbah mencapai separuh lebih. Apabila perhitungannya mulai saat penggergajian pembelahan hingga proses akhir yang dalam perhitungan peneliti limbahnya mencapai $37,08 \%$. Jadi bahan yang dapat digunakan dari kayu Perhutani mencapai 62,92\%. Sementara bila produk tersebut tanpa ukiran maka limbah yang dihasilkan adalah $34,21 \%$ dan kayu yang digunakan untuk pembuatan mebel mencapai $65,79 \%$.

\section{Saran}

Saran peneliti adalah bagaimana limbah-limbah tersebut dapat dimanfaatkan menjadi bahan sambungan atau komponen pendukung seperti Lamelo yang saat ini masih banyak impor. Di Jepara dapat diadakan industri papan blok dan papan partikel untuk pengolahan limbah. Atau kedepannya seperti penelitian Adam dkk (2019) dimana limbah kayu dapat dimanfaatkan sebagai bahan baku untuk komposit polimer kayu dalam mencetak 3D Printer.

\section{DAFTAR PUSTAKA}

Adam Pringle, Mark Rudnicki, Joshua Pearce. 2019. Wood Furniture Waste-Based Recycled 3-D PrintingFilament. https://hal.archives-ouvertes.fr/hal02111355. Submitted on $26 \mathrm{Apr}$ 2019 
Asosiasi Mebel dan Kerajinan Indonesia (AMKRI). 2015. Roadmap Industri Mebel dan Kerajinan Indonesia "Target Pencapaian Ekspor 5 Milyar USD". Jakarta.

Djoko Purwanto. 2009. Pengolahan Kayu Di Kalimantan Selatan.Jurnal Riset Industri Hasil Hutan Vol.1, No.1, Juni $2009: 14-20$.

https://ekonomi.kompas.com/read/2017/10/04/ 220000226

https://jepara.go.id/2018/09/04/pemkabjepara-akan-data-distribusi-kayu 